\title{
A New Technique Of Microcomputer \\ Based Overcurrent Relay
}

\author{
Mohammed Yahya Suliman
}

\section{Technical College/Mosul}

m yahya1973@yahoo.com

\begin{abstract}
A new technique of three phase overcurrent relay is described in this paper. The performance of the new design shows the ability to obtain any shape of characteristic using exponential type model with high accuracy. Also the new design used more accuracy, fast measurement for peak detection with error less than $2 \%$. The relay tested for normal and very inverse characteristics, also tested for line-to-line fault the results show the ability of discrimination the fault current and isolate the section of the system affected by a fault so that the remaining system can continue to operate normally.
\end{abstract}

Key-words: overcurrent relay, Peak detector, time coordination margin (TC), time multiplier setting (TMS), Programmable Peripheral Interface 8255 (PPI).

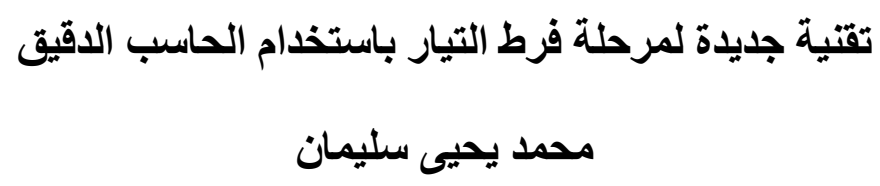

الكلية التقنية/الموصل 


\section{الخلاصة}

تضمن البحث تقنية جديدة في ملرحلة فرط التيار ثلاثية الطور. ان اداء التصميم

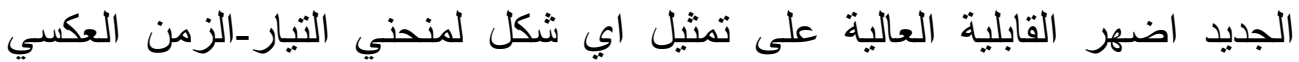

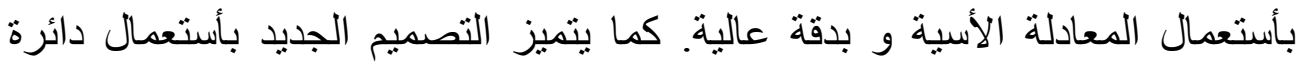

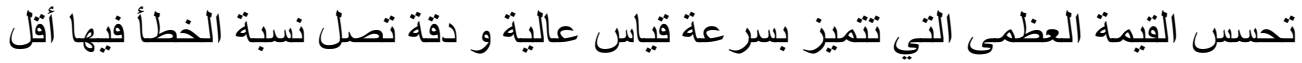

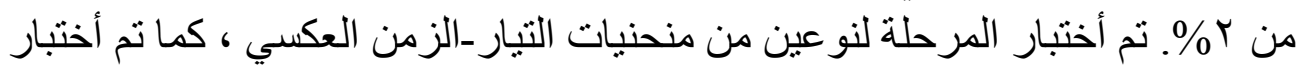

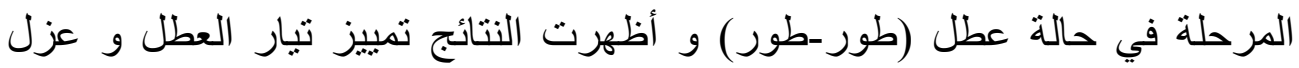
الجزء العاطل من الثبكة مع بقاء عمل باقي الثبكة بشكل طبيعي.

\section{Introduction}

Overcurrent protection is the simplest and least expensive form of fault protection that can be placed on transmission lines. The operating principles depend only on current magnitude. Phase overcurrent relays operate for all possible fault types, but require their pickup settings to be higher than the maximum expected normal or emergency load flow condition. Oververcurrent relays are widely used for the protection of radial transmission and distribution system [1].Such relays are relatively easy to set so that they will protect the system from short circuit faults in an adjacent component. Tripping may be instantaneous, delayed for a fixed time, or delayed for a time inversely proportional to the current magnitude. 
Figure 1 shows some of the various shapes of time/current characteristics that may be used [2].

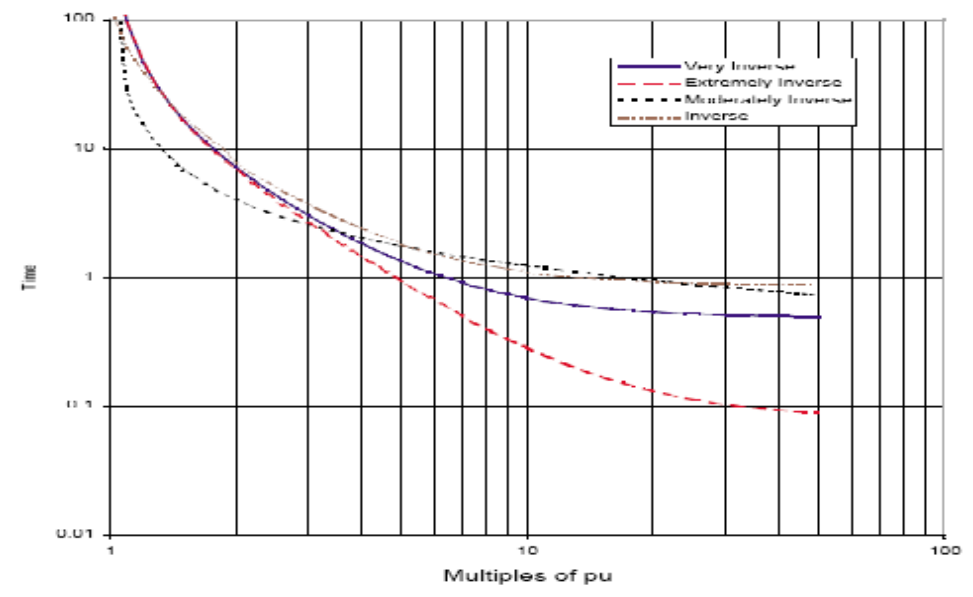

Fig 1 Time-current characteristics

\section{Protection Modeling}

In a system for which the fault current is practically determined by the fault location, without being substantially affected by changes in the power source impedance, it is advantageous to use inverse definite minimum time (IDMT) overcurrent protection. This protection provides reasonably fast tripping, even at a terminal close to the power source where the most severe faults can occur. When $Z_{S}$ (the impedance between the relay and the power source) is small compared with that of the protected section $Z_{\mathrm{L}}$, there is an appreciable difference between the current for a fault at the far end of the section $\left(E_{S} /\left(Z_{S}+Z_{L}\right), E_{S}\right.$ : source voltage), and the current for a fault at the near end $\left(E_{S} / Z_{S}\right)$. When operating time is inversely proportional to the current, the relay operates faster for a fault at the end of the section than the end nearer to the power 
source, and the operating time ratio for a fault at the near end to the far end is $Z_{S} /\left(Z_{S}+Z_{L}\right)[3]$.

The resultant time-distance characteristics are shown in Figure 2, for radial networks with several feeder sections. With the same selective time coordination margin TC which is the sum of the breaker, over travel, and factor-of-safety times, the operating time can be further reduced by using a more inverse characteristic.

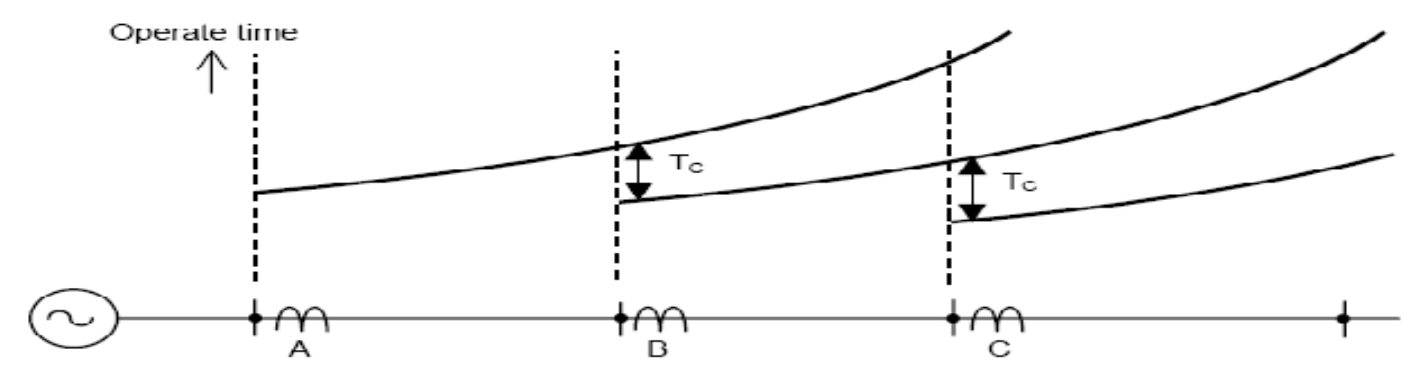

Fig 2 Time-distance Characteristics of Overcurrent Protection

The operating time of overcurrent protection elements have the IDMT (Inverse Definite Minimum Time) characteristics defined by equation (1) [4]:

$t=T M S x \quad\left\{\left[\frac{K}{\left(\frac{I}{I_{p}}\right)^{a}-1}\right]+c\right\}$

Where:

$\mathrm{t}=$ Operating time for constant current I (seconds) 
$\mathrm{I}=$ Energizing current (amps)

$\mathrm{I}_{\mathrm{P}}=$ overcurrent setting (amps)

TMS=time multiplier setting

$\mathrm{K}, \mathrm{a}, \mathrm{c}=$ constants defining curve

\section{Theory of measurement}

The current signals are taken from the CTs connected as in appendix A $[5,6]$.

To detect the fault current, the maximum value of the sinusoidal waveform current should be measured $[7,8]$.The instantaneous equation of the sinusoidal waveform current is:

$\mathrm{i}=\mathrm{I}_{\mathrm{m}} \operatorname{Sin}(\omega \mathrm{t})$

Where $I_{m}$ is the maximum value.

To measure the maximum value a peak value detector circuit is used, the circuit consists of TLC372 fast comparator and two operational amplifiers LM385. Figure 3 shows the circuit of the detector with lowimpedance output at $\mathrm{V}_{\text {OUT }}$, In addition, the TLC372 with high typical input impedance of $10^{12}$ eliminates any need for an input buffer stage, a feedback signal for the comparator acts as a reference level for comparison with the input signal's amplitude.

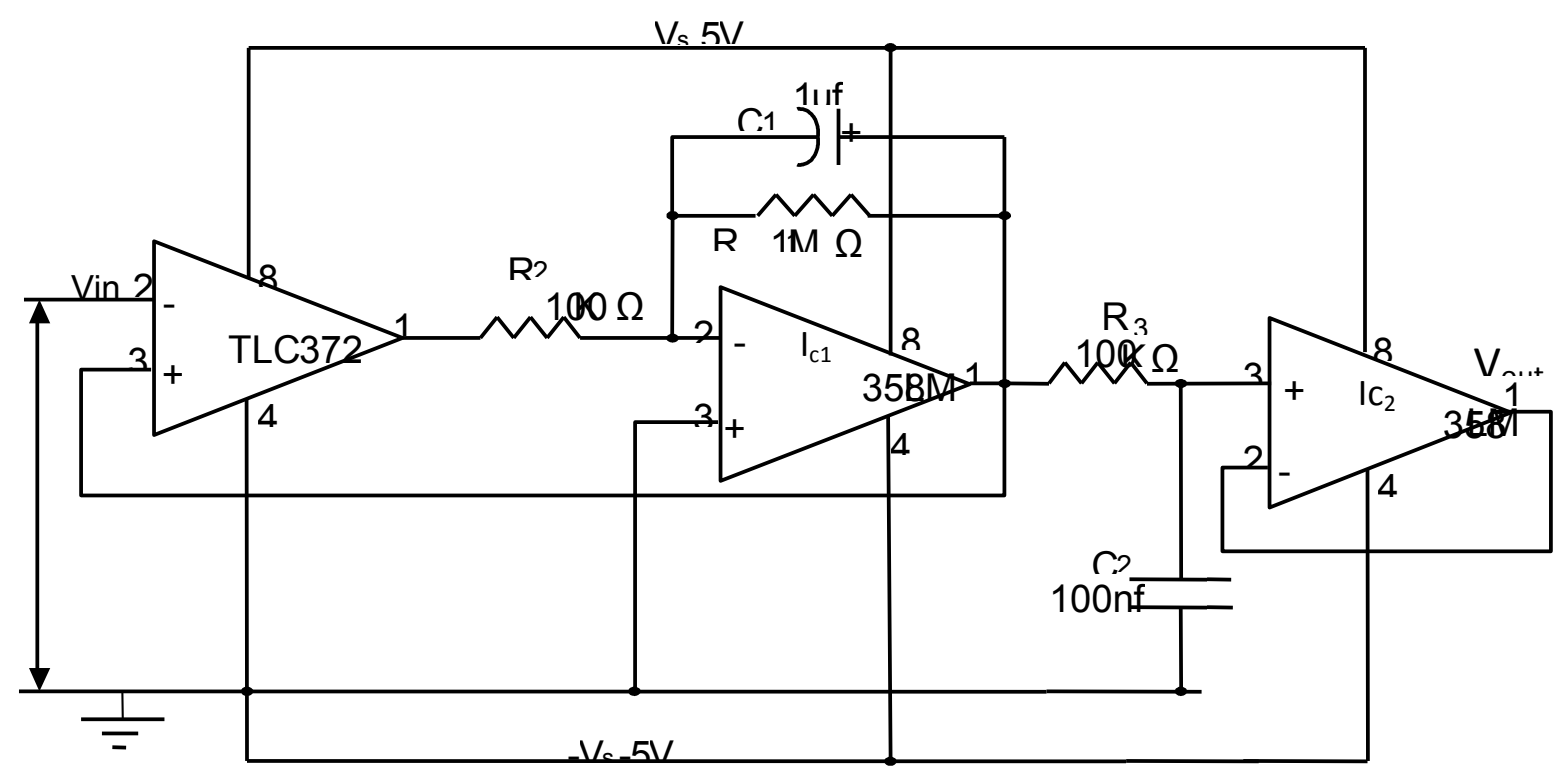


Fig 3 Peak value detector

When the input signal goes positive, the comparator's output turns on and sinks current through $\mathrm{R} 1$, charging current flows into $\mathrm{C}_{1}$ from $\mathrm{I}_{\mathrm{C} 1}$ and the output $\mathrm{V}_{\text {OUT }}$ rises to the point at which it slightly exceeds the peak level of $\mathrm{V}_{\mathrm{IN}}$, producing a dc level at $\mathrm{V}_{\text {OUT }}$ that closely approximate the positive peak level of the input waveform. The values of $\mathrm{R}_{1}, \mathrm{R}_{2}$, and $\mathrm{C}_{1}$ determine the ripple voltage on $\mathrm{V}_{\mathrm{OUT}}, \mathrm{I}_{\mathrm{Cl}}$ inverting input is held at virtual ground potential, so whenever $I_{C 1}$ 's output turns on, the voltage across $R_{1}$ approximately equals the negative-supply-rail voltage, -VS. Therefore, using a small value of $\mathrm{R}_{1}$ injects a relatively large pulse of current into $\mathrm{C} 1$, thus allowing the circuit to respond quickly to a sudden increase in input-signal amplitude "fast-attack" [9].

\section{System Design}

\section{1-Hardware System Design}

Figure 4 shows the block diagram arrangement of the protection system details in appendix C. From the figure, the programmable peripheral interface (PPI) is the main section of the interface system, which controls the input/output of the system that have 24 Input/Output ports grouped in 
three 8-bits parallel ports A, B and C these ports specify input or output ports by control register of PPI. The computer specifies these ports by ordering write control word and send it to store in the control register of PPI, In this system the control word is $82 \mathrm{H}$, according to the control word, $\mathrm{B}$ is the input port to input data, while $\mathrm{A}$ and $\mathrm{C}$ are the output ports port A for start of conversion of analog to digital converter and port $\mathrm{C}$ and the address of chip select of PPI is $400 \mathrm{H}$ and with address lines $\mathrm{A}_{0}$ and $\mathrm{A}_{1}$ according to the address lines port $\mathrm{A}$ is $401 \mathrm{H}$, port $\mathrm{B} 402 \mathrm{H}$ and port $\mathrm{C}$ is $403 \mathrm{H}$ respectively. The analogue multiplexer used to integrate the three phase signals is shown in figure 4 . The hardware system starts with initial input channels by the decoder to the control word of PPI to enable port B for input data from analog to digital converter and enable port $\mathrm{C}$ output port for select phase number through multiplexer to convert one value at each time to digital through analogue to digital converter, while port C8 to trip signal, port A give SC (Start of conversion), the result enter to the computer through data bus by port B of (PPI). The buffer circuit is located before PPI to protect it from the undesired value.

\section{2-Software System Design}

Figure 5 shows the flow chart arrangement for the software design of the overcurrent relay, the program is written in $\mathrm{C}$ language which is given in appendix B, start, with the initial input/output ports by sending the control word to control register of 8255 PPI, then initial input channels by the decoder to select the phase $\left(\mathrm{I}_{\mathrm{ph}}\right)$, then 10 samples to be taken at $(2 \mathrm{KHz})$ from peak value detector circuit. The peak amplitude current $\left(\mathrm{I}_{\max }\right)$ is compared with the setting point $\mathrm{I}_{\mathrm{pu}}$ (pickup current value). Tripping signal send to tripping circuit (after delay time obtained from equation 1) when the measured value exceed the pickup value. The execution time of the overcurrent relay was $10 \mathrm{msec}$.

\section{Discussion of the Results}

Figure 6 and Table 2 show the test circuit's sine-wave-frequency response by plotting the error in $\mathrm{V}_{\text {OUT }}$ for three peak levels of $\mathrm{V}_{\text {IN }}$. The figure show the error increase when frequency of the input signal increase so the circuit can be use in low frequency especially at $50 \mathrm{~Hz}$ with high accuracy. Figure 7 shows the input versus output of the peak value 
detector circuit where the output has a less than 2\% error. The experimental results for the overcurrent relay consists of two types

time-current characteristics normal inverse and very inverse respectively as shown in Figure 8 and figure 9 at three types of time multiplier setting $(\mathrm{TMS}=1,0.6,0.4)$, the coefficients of equation $1(\mathrm{k}$, a and $\mathrm{c})$ are listed in table 1. It can be noticed that good agreement is achieved between the practical design results and the published curves [2]. The advantages of the new design are fast measurement to the peak amplitude of the line current with high accuracy to make the relay sensitive to any abnormal condition also from the software design show the ability to obtain any shape of time-current characteristics by changing the value of the coefficients of equation 1 in the software program without need to change the hardware system.

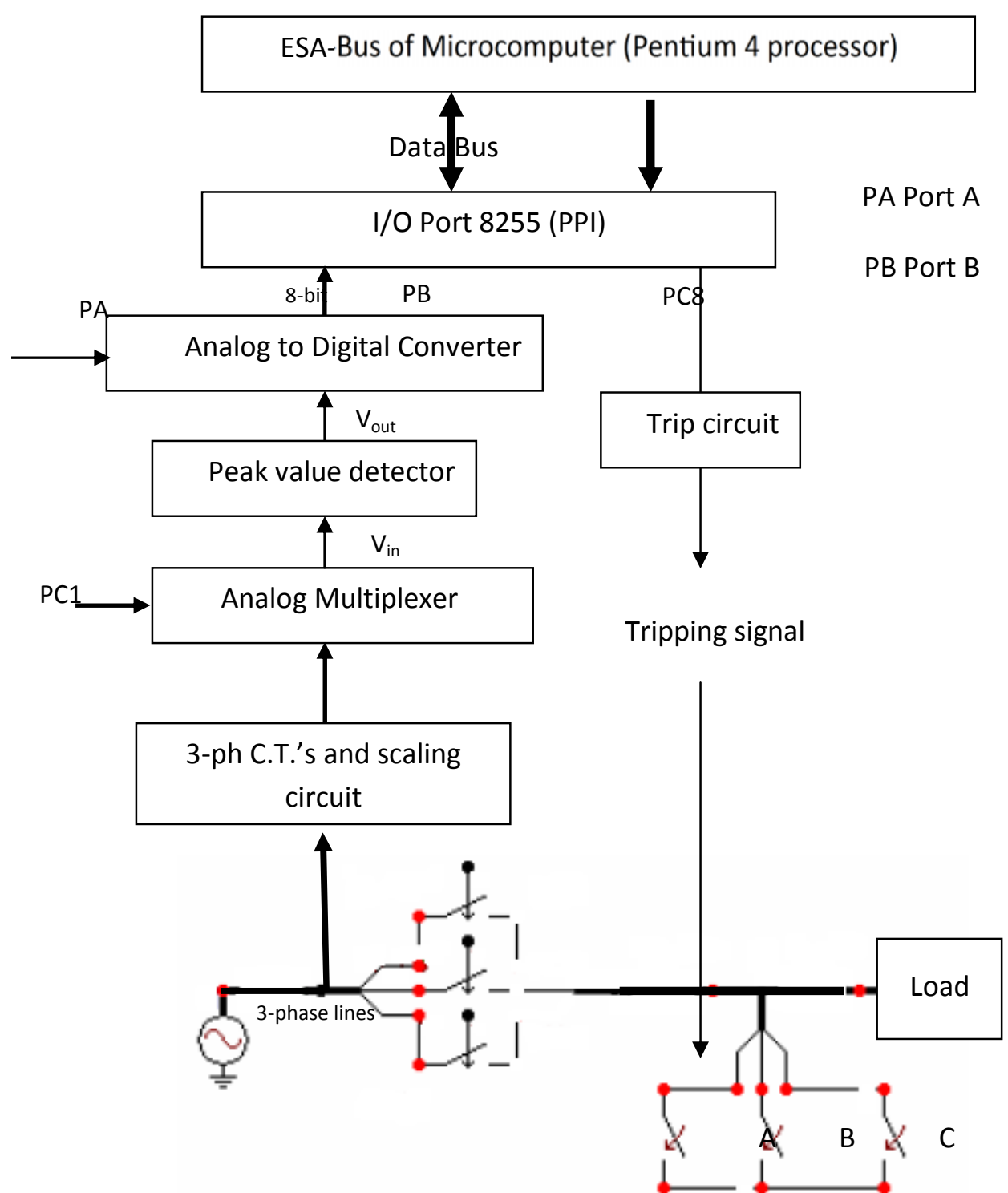



Fig 4 Block diagram of the protecon system

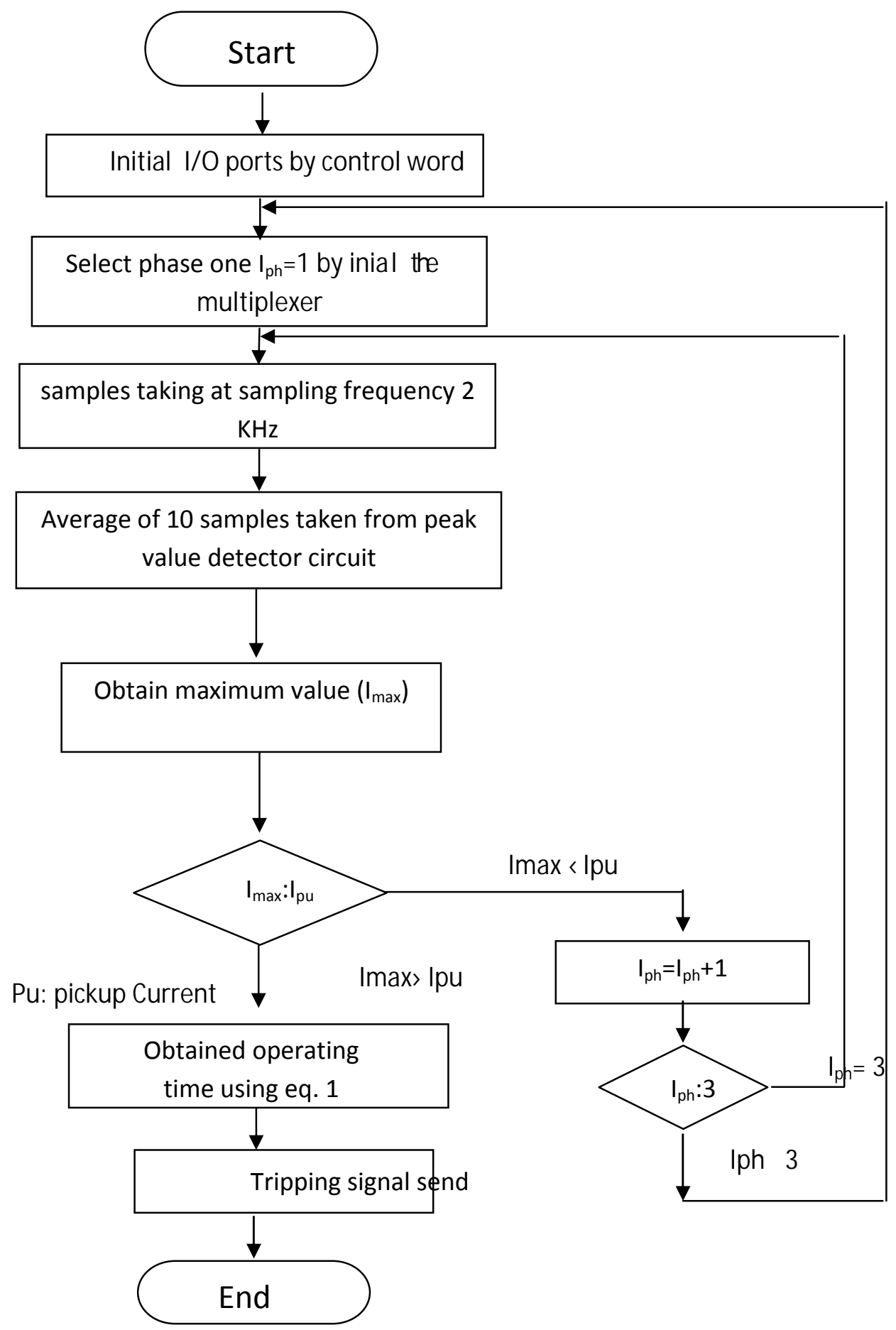


Fig 5 Flow chart of overcurrent relay

Table 1

\begin{tabular}{|l|l|l|l|}
\hline Relay Type & k & a & c \\
\hline
\end{tabular}




\begin{tabular}{|l|l|l|l|}
\hline Normal Inverse & 0.14 & 0.02 & 0 \\
\hline Very Inverse & 13 & 1 & 0 \\
\hline
\end{tabular}

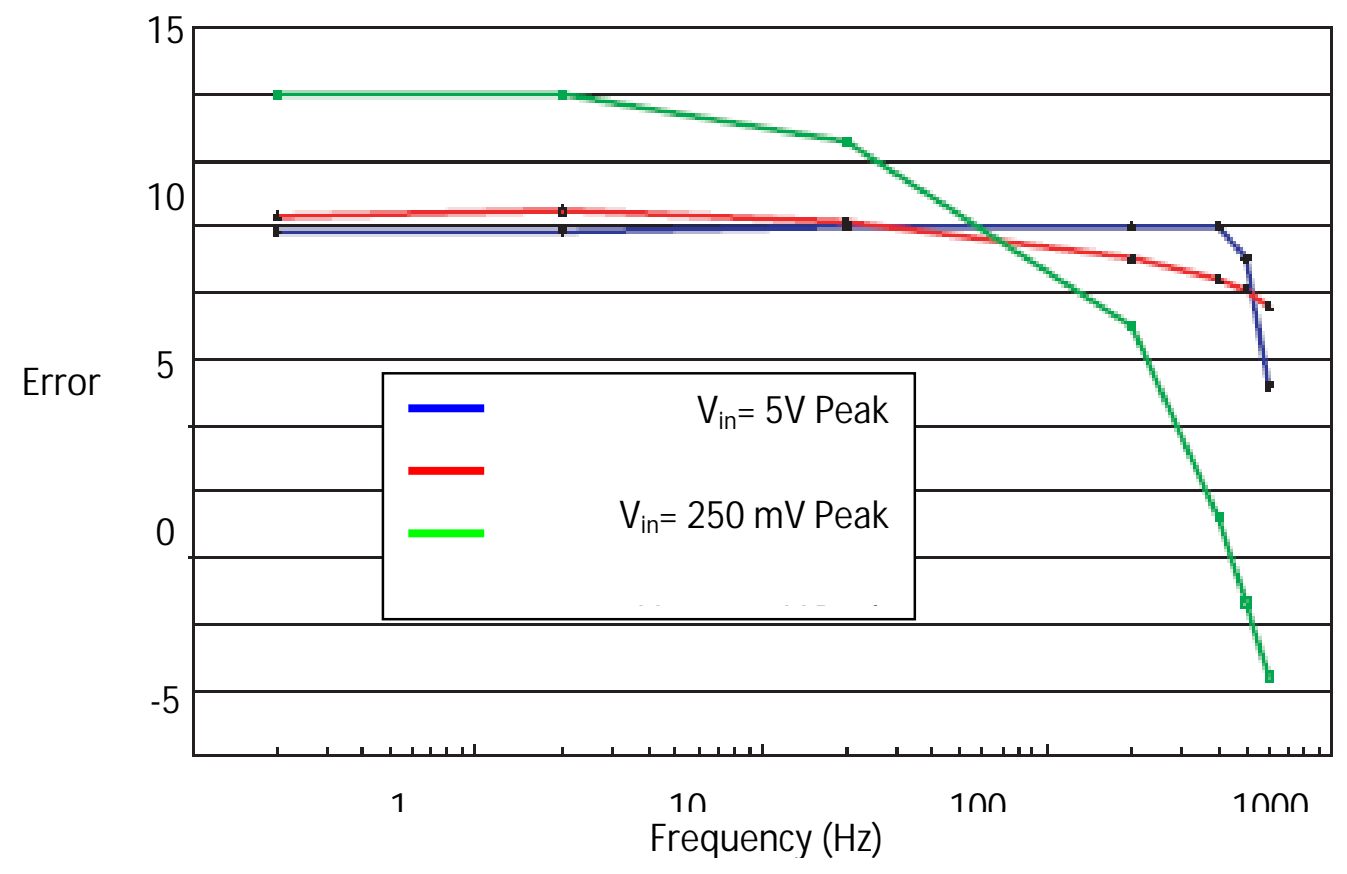

Fig 6 plon $g$ the $d$ ference pet ve en pak s gal lerel s and ait put wol tage for thr e peak levels illustrates the detector's frequency response.

Second advantage all three phase current are common in comparison with the multiple of pick up value and one characteristic curve is representing 
all three phase lines. Figure 10 show the operation of the over current relay under fault condition, here fault occurs when $\mathrm{t}=100 \mathrm{~ms}$. Responding to phase-phase fault type (Phase B and Phase C). Its shows that this overcurrent relay can operate properly within about one cycle after fault occurs. Also the relay distinguishes between the steady state fault and the transient conditions.

\section{Conclusion:}

The new technique of overcurrent relay show fast measuring to the peak amplitude of phase current with high accuracy also gives the ability to obtain any type of inverse time-current characteristic by changing the coefficients of equation 1 in the software program with high range of time multiplier setting (TMS). This is important in radial protection system also it has the ability to isolate any type of fault in about one cycle after fault occurs as shown in figure 10 .

\begin{tabular}{|c|c|c|c|}
\hline $\begin{array}{c}\text { Frequency } \\
(\mathrm{Hz})\end{array}$ & $\begin{array}{c}\text { Error } \\
\mathrm{V}_{\text {in }}=5 \mathrm{~V} \\
\text { Peak (\%) }\end{array}$ & $\begin{array}{c}\text { Error } \mathrm{V}_{\text {in }}=250 \mathrm{mV} \\
\text { Peak (\%) }\end{array}$ & $\begin{array}{c}\text { Error } \\
\mathrm{V}_{\text {in }}=25 \mathrm{mV} \\
\text { Peak (\%) }\end{array}$ \\
\hline 1 & -0.4 & 0.8 & 10 \\
\hline 10 & -0.4 & 1.2 & 10 \\
\hline 50 & 0 & 0.4 & 6.4 \\
\hline 100 & 0 & -2.4 & -7.6 \\
\hline 200 & -2.4 & -4 & -22 \\
\hline 10000 & -12 & -4.8 & -28.4 \\
\hline
\end{tabular}

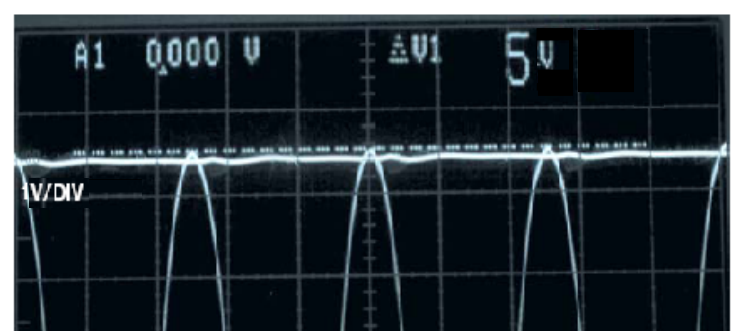


Fig 9 Time current characterisc for
Fig 10 Phase currents when B-C phase fault occurs

\section{References}

1-IEEE Guide for Protective Relay Applications to Transmission Lines, sept. 2000

2- Arun Phadke, "Power System Protection”, CRC Press 2001.

3- Abdul Saha and Abbas, "Microprocessor based fast system for measuring power, and peak amplitude of voltage and current “, IE (I) Journal-ET vol. 69,feb. 1989, pp56-58. 
4- ArturoConde, Emesto Vazquez, "A Time Overcurrent Adaptive Relay", International Journal of Electrical Power and Energy Systems, Vol.-25, Issue-10, Dec 2003 pp. 841-847.

5- Abd-AL-Satar "Microprocessor Controlled overcurrent relay for three phase system”, M.Sc. thesis, University of Mosul, Mosul, 1994.

6- GE Power Mangement "Tow vs. Three overcurrent Elements for Phase Fault Protection in Feeder Relays" Technical Notes, 2000.

7-Dinesh Birla and Rudra Prakash "Time-Overcurrent relay Coordination", International Journal of Emerging Electric Power Systems, vol. 2, Issue2, 2005.

8- Mark Brown, Ben Ramesh "Practical Power Systems Protection", Elsevier Press 2004.

9- Anthony H Smith, Scitech "Inexpensive peak detector requires few components", EDN Journal, Jul 2000.

\section{Appendix A}

CT's are in wye connected with phase and ground relays. The currents Ia, $\mathrm{Ib}$, and Ic are the vector currents, and the CT ratio is assumed to be $1 / 1$ to simplify the mathematics. Vectorially, the primary and secondary currents are inphase, neglecting phase-angle errors in the CT's.

The symmetrical-component method of analysis is a powerful tool, not only for use in calculating the power-system currents and voltages for unbalanced faults but also for analyzing the response of protective relays. In terms of phase-sequence components of the power-system currents, the output of wye-connected CT's is as follows:

$\mathrm{Ia}=\mathrm{Ia}_{1}+\mathrm{Ia}_{2}+\mathrm{Ia}_{0}$

$\mathrm{Ib}=\mathrm{Ib}_{1}+\mathrm{Ib}_{2}+\mathrm{Ib}_{0}=\mathrm{a}^{2} \mathrm{Ia}_{1}+\mathrm{aIa}_{2}+\mathrm{Ia}_{0}$ ..(a-2) 
$\mathrm{Ic}=\mathrm{Ic}_{1}+\mathrm{Ic}_{2}+\mathrm{Ic}_{0}=\mathrm{aIa}_{1}+\mathrm{a}^{2} \mathrm{Ia}_{2}+\mathrm{Ia}_{0}$ ..(a-3)

$\mathrm{Ia}+\mathrm{Ib}+\mathrm{Ic}=\mathrm{Ia}_{0}+\mathrm{Ib}_{0}+\mathrm{Ic}_{0}=3 \mathrm{Ia}_{0}=3 \mathrm{Ib}_{0}=3 \mathrm{Ic}_{0}$ ..(a-4)

Where 1, 2, and 0 designate the positive-, negative-, and zero-phasesequence components, respectively, and where ' $\mathrm{a}$ ' and ' $\mathrm{a}^{21}$ are operators that rotate a quantity counterclockwise $120^{\circ}$ and $240^{\circ}$, respectively. The connection of the C.Ts of designed three phase overcurrent relay shown below, the resistance (burden) that connect across the secondary of C.T.:

Burden $($ in $\mathrm{VA})=\mathrm{I}_{\mathrm{s}}^{2} \mathrm{R}$

Where:

$\mathrm{R}$ : resistance

$\mathrm{I}_{\mathrm{s}}:$ secondary current

The resistance connected across the secondary to convert the line current to

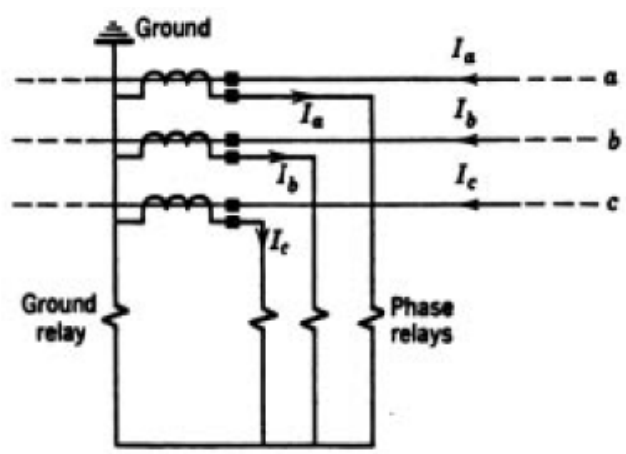
voltage in the range of analog to digital converter $( \pm 5 \mathrm{~V})$.

\section{Appendix B}

The software program of three phase over current relay

\#include $<$ stdio.h $>$

\#include $<$ dos.h $>$ 
\#include $<$ math.h $>$

\#define pi $4 *$ atan

\#define $\operatorname{cosec}(\mathrm{x}) 1 / \sin (\mathrm{x})$

$\operatorname{main}()\{$

unsigned int $\mathrm{a}[10], \mathrm{c}[10]$;

int z,I,h,l,he,g,j,l,sum,v,t,q;

outportb $(0 \mathrm{x} 403,0 \mathrm{x} 82)$

for $($ he $=0 \times 80 ;$ he $<=0 \times 82 ;$ he ++$)\{\quad / *$ phase selection $* /$

outportb(0x402,he);

label sum $=0$;

for $\left(\mathrm{z}=1 ; \mathrm{z}^{<}=10 ; \mathrm{z}^{++}\right)\{$

$\mathrm{a}[\mathrm{z}]=\operatorname{inportb}(0 \mathrm{x} 401) ; / *$ Input samples */

$\mathrm{c}[\mathrm{z}]=\mathrm{a}[\mathrm{z}] * 0,039-5 ; \quad / *$ convert to analog $* /$

if $(\mathrm{g}>=-0.039) \mid(\mathrm{g}<=0.039)$ goto label;

sum $=$ sum +1 ;

$\mathrm{v}=$ sum $/ 5.5 \quad / *$ setting pickup $* /$

while $(\mathrm{v}>=1)\{$

$\mathrm{t}=\operatorname{pow}(\mathrm{v}, 1) ; \mathrm{q}=2500 / \mathrm{t} ; \quad \quad / *$ time setting */

$\operatorname{delay}(q)$;

outportb $(0 \mathrm{x} 400,1) ; / *$ trip signal to circuit breaker */

end: 


\section{Appendix C}

The interface and analog to digital conversion connection of the designed relay

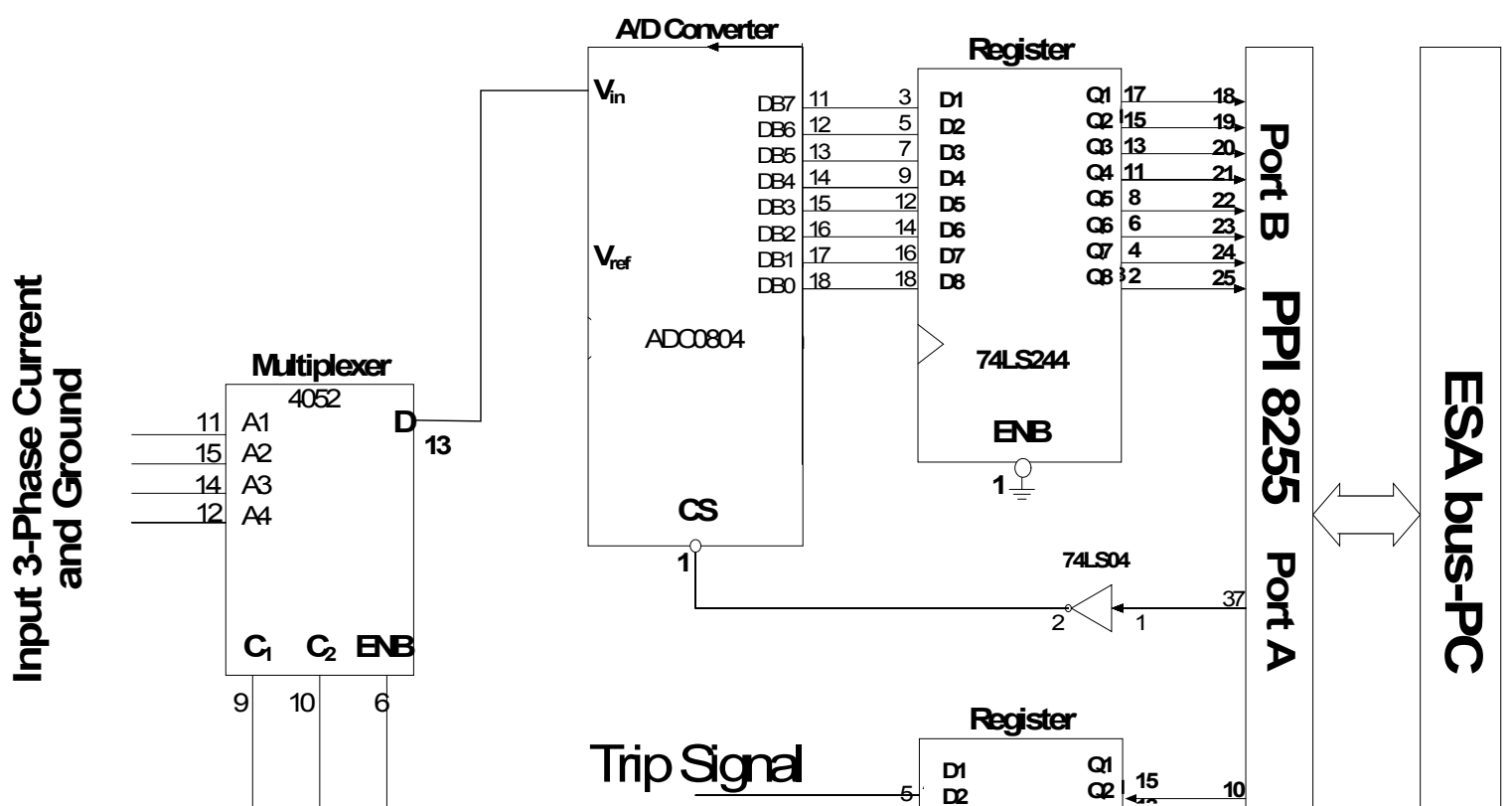




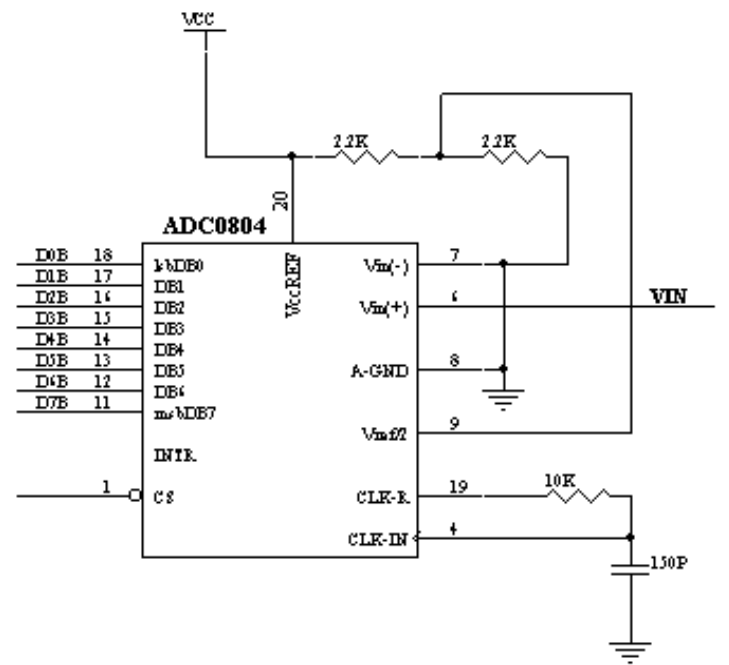


The work was carried out at the college of Engg. University of M osul 